\title{
Xavier Mina, el insurgente español: guerrillero por la libertad de España y México
}

\author{
Eduardo Adán Orozco Piñón (D) https://orcid.org/0000-(0003-1266-1941 \\ Facultad de Filosofía y Letras \\ Universidad Nacional Autónoma de México, México \\ edorozcop@gmail.com
}

Gustavo Pérez Rodríguez, Xavier Mina, el insurgente español: guerrillero por la libertad de España y México, México, Instituto de Investigaciones Históricas-Universidad Nacional Autónoma de México/Secretaría de Desarrollo Institucional/Seminario de Investigación sobre Historia y Memorias Nacionales, 2018, 446 p. (Serie Historia Novohispana, 105).

Xavier Mina es uno de los personajes más emblemáticos de la historia de México. Sobre su figura se ha construido, a lo largo de dos siglos, un halo de heroicidad fácilmente reconocible por la gran mayoría de mexicanos. Debido a ello, este personaje es de los más queridos y, al mismo tiempo, peor comprendidos del panteón histórico nacional. La obra de Gustavo Pérez Rodríguez, Xavier Mina, el insurgente español ha llegado como paliativo ante el desconocimiento generalizado de la vida del guerrillero navarro, pues a través de sus páginas se le estudia totalmente alejado de la historiografía nacionalista de siglos pasados.

Este libro rompe los paradigmas del género biográfico dentro de la historiografía mexicana. Las semblanzas de personalidades del proceso de independencia elaboradas en la última década por historiadores académicos se han caracterizado por utilizar a su sujeto de estudio como eje narrativo que permita estudiar el contexto de la época y/o la construcción historiográfica de su respectivo personaje, dejando de lado el relato de la vida cotidiana del biografiado, es decir, lo que se gana en análisis se pierde en narración. 
Si bien Pérez Rodríguez ha construido una obra que cumple con los estándares académicos tradicionales -donde priman el rigor y el apego al dato que ofrecen las fuentes, la reconstrucción de contextos históricos a partir de las mismas, así como la construcción de modelos conceptuales que ayuden a ahondar en una discusión historiográfica determinada-, el alcance de la obra va más allá de lo puramente histórico, puesto que el autor ha dado rienda suelta a su pluma, guiado por un claro entusiasmo hacia Mina, que le ha permitido ofrecer a los lectores un libro de historia narrativa muy bien logrado, combinando acertadamente investigación histórica con narración literaria.

Gustavo Pérez divide su obra en cuatro grandes capítulos, cada uno más extenso que el anterior. El primero de ellos, "La insurgencia en España”, se enfoca en la infancia y juventud de Xavier Mina, en sus estudios, sus relaciones familiares -y hasta amorosas-, para después adentrarse en la invasión de Napoleón Bonaparte a la Península Ibérica, explicando el juego geopolítico bonapartista, y detallando con mucha precisión los movimientos de Mina como guerrillero defensor de España. Echando mano de la historia militar el autor explica las batallas, los itinerarios, las tácticas y las estrategias de guerrilleros y franceses. De esta manera se va develando el cómo y el por qué el navarro va adquiriendo prestigio y fama, tanto entre los aliados como entre los enemigos. Ya desde este primer apartado, Pérez Rodríguez comienza a resquebrajar la estatua de bronce, que por tanto tiempo ha encerrado al personaje, al mostrar que, ante su cautiverio en Francia, Mina ofreció sus servicios a la causa napoleónica si esto le significaba la libertad. El héroe baja del pedestal para ponerse ante los lectores como un hombre común, con virtudes y con defectos. En la parte final de este capítulo, el lector comenzará a ver la transformación de Xavier Mina en un convencido liberal partidario del republicanismo en las naciones americanas. 
Lo que el primer capítulo ganó en cuanto a reconstrucción histórica a través de la abundante documentación de la época, el segundo -que lleva por nombre "El camino a la Nueva España” - lo perdió, convirtiéndose en un excelente resumen del trabajo de Guadalupe Jiménez Codinach, La Gran Bretaña y la independencia de México. Este capítulo constituye una radiografía del juego geopolítico de las primeras décadas del siglo XIX y de las intenciones de las grandes potencias del viejo continente ante las revoluciones americanas, cada una buscando promover sus propios intereses y, de ser posible, perjudicar a sus adversarios. A lo largo de este apartado los lectores podrán enterarse de los intereses económicos de los ingleses en los territorios de la América española, toda vez que el autor desenmaraña la red de comerciantes británicos, de comandantes estadunidenses y de refugiados españoles implicados en la expedición de Mina. Una virtud mayúscula de este capítulo es que desfilan ante los ojos del lector una miríada de personajes históricos sumamente conocidos que interactúan e influyen, de una u otra manera, en la formación ideológica del joven guerrillero y en el desarrollo de su proyecto: Winfield Scott, Simón Bolívar, Servando Teresa de Mier, Lord Holland, Guadalupe Victoria, Cornelio Ortiz de Zárate, el comodoro Aury -más conocido para las independencias sudamericanas- y Alexandre Petión, presidente de Haití. Este desfile de personalidades ayuda a que los lectores entiendan la escala global de las acciones de Xavier Mina y que comprendan que el siglo XIX era ya un mundo completamente comunicado en el que circulaban ideas entre continentes. Es entonces cuando comienza a plantearse una inquietud: ¿es un individuo producto de su contexto o el contexto es modelado por un individuo? El autor deja que los lectores resuelvan esta interrogante.

El capítulo tercero, "La insurgencia en la Nueva España”, nos adentra a las acciones militares de Mina en territorio novohispano, sabemos la historia grosso modo. La expedición desembarcó en las costas de Tampico y avanzó al interior del virreinato buscando hacer Secuencia. E-ISSN 2395-8464 
contacto con los grupos insurgentes. El autor expone el viaje de Mina rumbo al Bajío para sumarse a los rebeldes que reconocían la autoridad del gobierno de la Junta de Jaujilla. Este tercer apartado narra de manera detallada las primeras acciones militares de la "División Auxiliar de la República Mexicana”, demostrando las virtudes de Mina como comandante tras salir victorioso en los primeros encuentros con las fuerzas virreinales. A través de los testimonios escritos de los sobrevivientes de la División Auxiliar, y de la correspondencia de Mina, así como la de comandantes realistas, virrey incluido, es que el autor lograr reconstruir -apoyado también en mapas y planos de la época- la ruta y las batallas que libra Xavier Mina en Nueva España. Punto importante y curioso, es el retrato que se hace del virrey Juan Ruiz de Apodaca, a quien el autor presenta como un competente comandante militar que echa mano de todos sus recursos para detener el avance de la División de Mina: envía hombres, armas, municiones, pertrechos, órdenes, despachos; documentos van y vienen para lograr la victoria del lado virreinal. Esta descripción de Apodaca en 1817 contrasta con su actuación en 1821. Durante la rebelión de Iturbide, el conde del Venadito se mostró indeciso y tardío para combatirla, actitud que es plenamente contraria ante la amenaza del expedicionario navarro, y que ha dado pie a que algunos especialistas en el periodo de la consumación vean una colusión entre ambos jefes.

El último capítulo, “Mina y los insurgentes: auge y ocaso”, nos adentra en la etapa final de las acciones realizadas en Nueva España por el antiguo guerrillero y su División Auxiliar. Con las mismas fuentes -memorias, correspondencia, planos, mapas, partes militares, prensa como la Gaceta del Gobierno de México-, el autor reconstruye la campaña militar de Xavier Mina en Guanajuato, en torno a los fuertes del Sombrero y de los Remedios, donde realizó acciones conjuntas con las tropas del comandante insurgente Pedro Moreno. Por otra parte, el lector podrá adentrarse en los planteamientos estratégicos de los virreinales, quienes Secuencia. E-ISSN 2395-8464 
comenzaron a cercar a Mina hasta formalizar un sitio al fuerte del Sombrero que paulatinamente irá mermando las fuerzas y el espíritu combativo de la División Auxiliar. El autor narra con objetividad el desastre que destruirá a la expedición: las derrotas que sufre Mina ante las fuerzas virreinales, la destrucción del fuerte de Soto la Marina, la captura de Servando Teresa de Mier, el asesinato de los compañeros de armas, las deserciones y los “chaquetazos".

Mención aparte merecen las disputas que se generaron entre los comandantes insurgentes y los miembros de la Junta de Jaujilla. Un ejemplo emblemático es el del padre Torres, a cargo del fuerte de los Remedios, a quien el autor deja muy mal parado al pintarlo como un traidor, egoísta y envidioso. La desorganización dentro de las filas rebeldes -que ya apunta a que no existía un solo tipo de insurgencia - dejará huella en el joven Mina, pues consideró que los americanos rebeldes eran hombres “despreciables”.

El gran aporte historiográfico de la obra de Gustavo Pérez reside en los apartados tercero y cuarto, en ellos se ofrece una aproximación a la época menos explorada de la guerra de independencia, 1816-1820, años correspondientes al embate pacificador del absolutismo fernandino que no han sido lo suficientemente estudiados por los historiadores. En ese sentido, el Xavier Mina, permite observar fenómenos interesantes en el ámbito de la estructura militar del virreinato hacia 1817 , -a pesar de que esto no es uno de los objetivos de la obraempezando por confirmar que existían varias insurgencias totalmente dispersas y mal coordinadas entre sí. Esta situación no era exclusiva de los rebeldes, ya que también queda perfectamente plasmada la descoordinación que existió entre el virrey Juan Ruiz de Apodaca con sus comandantes generales. La correspondencia de la que abreva la obra de Pérez Rodríguez refleja este problema, de tal manera que no cabe duda del nivel de dispersión dentro de las propias fuerzas armadas virreinales. Tomemos como ejemplo a Joaquín de Arredondo, Secuencia. E-ISSN 2395-8464 
comandante general de las Provincias Internas de Oriente, inicial teatro de operaciones de Mina, quien en varias ocasiones desobedeció abiertamente las órdenes del virrey Apodaca.

Estas situaciones, que se muestran tangencialmente en la obra de Gustavo Pérez, sirven como indicador del siguiente problema para las autoridades virreinales: desde 1813 Félix María Calleja implementó un Reglamento político militar con la intención de involucrar a las comunidades en la defensa del reino a través de la creación de nuevos cuerpos de milicia urbana, de manera que el resto del ejército de línea y de otros grupos milicianos quedaron libres para combatir a la insurgencia. El Plan Calleja buscaba centralizar el mando militar en la figura del virrey, quien también era el Capitán General, con la intención de coordinar acciones de manera acertada y eficaz contra los rebeldes. Pérez Rodríguez muestra que, a pesar de los esfuerzos, hacia 1817 el aparato defensivo de la Nueva España no funcionó como se pretendía, debido a la dispersión de cuerpos militares producida por el Plan Calleja.

Estamos, pues, ante una obra que, por un lado, ofrece a los lectores neófitos una gran riqueza narrativa, a manera de novela de aventuras y, por otro, ofrece al lector especializado una excelente radiografía de la estructura y la operatividad militar de Nueva España en la época del embate absolutista de Fernando VII. De ser bien distribuido, el Xavier Mina de Gustavo Pérez Rodríguez se convertirá en una de las biografías históricas más importantes de la década que termina. 